\title{
İkiz Açık Hipotezi ve Ters Nedensellik: Türkiye Ekonomisi Üzerine Ampirik Bir Çalışma
}

\section{Twin Deficit Hypothesis and Reverse Causality: An Empirical Study on Turkish Economy}

\author{
Meltem DUĞRU ${ }^{1}$ (D)
}

\section{Öz}

İkiz açık hipotezi, cari açık ve bütçe açıklarının birlikte hareket ettiğini ileri süren bir hipotezdir. Bu hipoteze göre iki değişken arasındaki ilişkinin varlığı farklı şekillerde ele alınmaktadır. Geleneksel Keynesyen Görüş, bütçe açığından cari açığa doğru bir nedensellik olduğunu savunurken, Ricardocu Denklik Hipotezi iki değişken arasında herhangi bir ilişkinin olmadığını iddia etmektedir. Lawrence H. Summers tarafından adlandırıımış olan Cari Iş̧lemler Hedeflemesi görüşü ise, Keynesyen teorinin aksine cari açıktan bütçe açığına doğru bir nedensellik olduğu yönündedir. 1980'li yıllarda yaşanan serbestleşme sonucunda hem gelişmiş hem de gelişmekte olan ülkeleri etkileyen ikiz açık, günümüzde ülkelerin sorunu olmaya devam etmektedir. Bu çalışmada, Türkiye'nin cari açık ve bütçe açığı değişkenleri arasında herhangi bir etkileşimin olup olmadığı araştırılmıştır. Bu etkileşimin yönünün ve derecesinin belirlenmesi için 2009:1Q ve 2020:2Q dönemleri arasında 'ikiz açık hipotezi çerçevesinde ters nedensellik' kavramının varlığı ile ilgili bir sonuç elde edilmeye çalışıımıştır. Zaman serileri olarak derlenen bütçe açığı ve cari açık verileri için eşbütünleşme analizi ve Otoregresif Dağıtıımış Gecikme modeli yaklaşımına dayalı sınır testi uygulanmıştır. Ardından Hata Düzeltme Modeli kapsamında nedenselliğin yönü belirlenmiştir. Yapılan analizler sonucunda iki değişken arasındaki ilişkinin yönünün uzun dönemde negatif, kısa dönemde pozitif olduğu tespit edilmiştir. Bu sonuçlara göre, Cari İşlemler Hedeflemesi görüşü kısa dönem bulguları ile desteklenirken, Keynesyen görüş reddedilmektedir.

Anahtar kelimeler: Cari açık, Bütçe açığı, İkiz açık - cari işlemler hedeflemesi

JEL Sınıflaması: E21, E60, F41, H62

\section{ABSTRACT}

The twin deficit hypothesis is a hypothesis suggesting that the current deficit and the budget deficit move together. According to this hypothesis, the existence of a relationship between two

'Trakya Üniversitesi, Uzunköprü Uygulamalı Bilimler Yüksekokulu, Bankacilık ve Sigortacılık Bölümü Üniversite, Edirne, Türkiye

ORCID: M.D. 0000-0003-4280-5651

Sorumlu yazar/Corresponding author: Meltem DUČRU,

Trakya Üniversitesi, Uzunköprü Uygulamalı Bilimler Yüksekokulu, Bankacılık ve Sigortacılık Bölümü Üniversite, Edirne, Türkiye

E-posta/E-mail: meltemdugru@trakya.edu.tr

Başvuru/Submitted: 25.11.2020 Revizyon Talebi/Revision Requested: 26.12.2020 Son Revizyon/Last Revision Received: 26.12.2020

Kabul/Accepted: 27.12 .2020

Atıf/Citation: Dugru, M. (2020). İkiz açık hipotezi ve ters nedensellik: Türkiye ekonomisi üzerine ampirik bir çalışma. Istanbul iktisat Dergisi - Istanbul Journal of Economics, 70(2), 415-437. https://doi.org/10.26650/ISTJECON2020-831500 
variables is handled in different ways. While the Traditional Keynesian View argues that there is causality from the budget deficit to the current deficit, the Ricardian Equivalence Hypothesis claims that there is no relationship between two variables. The Current Account Targeting view, named by Summers, is that there is causality from the current deficit to the budget deficit, contrary to the Keynesian theory. The twin deficit, affecting both developed and developing countries as a result of liberalization experienced in the 1980s, continues to be the problem of countries today. In this study, Turkey's current deficit and budget deficit were investigated whether there was any interaction between these variables. In order to determine the direction and degree of this interaction, it was tried to obtain a result about the existence of the concept of reverse causality within the framework of the "twin deficit hypothesis" between 2009: 1Q and 2020: 2Q. For the budget deficit and current deficit data compiled as time series, cointegration analysis and the bound test based on the Autoregressive Distributed Lag model approach were applied. Then, the direction of causality was determined with the Error Correction Model. As a result of the analysis, it was determined that the direction of the relationship between two variables is negative in the long term and positive in the short term. According to these results, while the Current Account Targeting view is supported by the short term findings, the Keynesian view is rejected.

Keywords: Current deficit, Budget deficit, Twin deficit hypothesis - current account targeting JEL Classification: E21, E60, F41, H62

\section{EXTENDED ABSTRACT}

The twin deficit hypothesis is a hypothesis suggesting that the current deficit and the budget deficit move together. While the Traditional Keynesian View argues that there is causality from the budget deficit to the current deficit, the Ricardian Equivalence Hypothesis claims that there is no relationship between two variables. According to the Ricardian view, if the economic administration reduces taxes or goes into borrowing, it will increase the savings of individuals. Because individuals are rational, they are aware that tax cuts in the current period will lead to tax increases in the future. For this reason, they will prefer to save rather than spend on consumption. Another view on the twin deficit is the current account targeting view which is the subject of our study. The current account targeting view, named by Summers, is that, contrary to the Keynesian theory, there is causality from the current deficit to the budget deficit. Summers (1988, p. 349386) stated in his study that as a result of a large capital flows, the debts of countries will accumulate and indirectly cause a deficit in the budget.

Remembering the concept of the twin deficit after the 2008 financial crisis has led to more research on this issue. Budget deficit and current deficit, which have been among the problems experienced for years, are the variables of the twin 
deficit hypothesis. Today, still being in the nature of a problem for Turkey indicates that these variables need to be investigated. Therefore, it is important to know whether there is any interaction between the budget deficit and current deficit variables for Turkey which is an emerging economy. If there is an interaction, the direction and degree of this interaction must be determined. Thus, it is expected to provide more positive results of the economic policies to be implemented in Turkey and decisions to be taken in this direction.

Most of the studies in the literature investigated how these two variables affect each other and reached various results. In this study, the Current Account Targeting view is analyzed, which inquires whether there is causality from the current deficit to the budget deficit. The Current Account Targeting view within the framework in the period between 2009 and 2020 were investigated whether the current deficit affects the budget deficit in Turkish economy. In the study, first, the stationarities of the series were examined, and their levels were determined. In the next stage, for the budget deficit and current deficit data are compiled as time series, cointegration analysis and the bound test based on the Autoregressive Distributed Lag model approach were applied. As a result of these tests, long-term results between the variables of current deficit and budget deficit have been reached. Then, the Error Correction Model (ECM) was applied and the short-term results between two variables were interpreted within the scope of this model.

As a result of the analysis, a statistically significant relationship was found between two variables in the long and short term. Although the direction of the relationship between the current deficit and the budget deficit was negative in the long term, it was found to be significant. When the short term was analyzed, a positive and significant relationship was found. It was determined that while the current deficit variable affects the budget deficit in the same direction in the short term, it affects in the opposite direction in the long term in Turkey. According to the results of the analysis, it has been confirmed that the Current Account Deficit Targeting view, which is not supported in the long term, is supported in the short term. 


\section{Giriş}

1980 'li yıllar dünya ekonomilerinin serbestleşmeye başladı̆̆ı ve dışa açılma faaliyetlerinin yaygınlaş̧ığı yıllardır. Bu dönemde ülkeler arasındaki sermaye hareketliliğinin artmış olduğu görülmektedir. Ancak bazı ülkelerin ekonomik ilişkilerini dışa kapalı olarak sürdürmek istemeleri bazı sorunların ortaya çıkmasına neden olmuştur. Özellikle Amerika Birleşik Devletleri (ABD)'nde Reagan döneminde uygulanan muazzam vergi indirimleri ve bunun devamında gelen harcama artışları ile sosyal sigorta harcamalarının büyümesi ve ulusal borç faiz oranındaki artış bütçe açığında da ani bir yükselmeye neden olmuştur. Yaşanan bu gelişmeler neticesinde özel tasarruflar yüzde 90'dan fazla azalmıştır. Bu tasarruf düşüşü, 1980'li yılların ilk yarısında sermaye girişleri ile dengelenmek istense bile sonuç değişmemiştir. Yine bu dönemde doların dalgalanmaya bırakılması ile birlikte sermaye kontrollerinin olmaması ayrıca bir sorun teşkil etmiştir. Federal Rezerv'in enflasyona karşı sert bir duruş sergilemesi, ortaya çıkan mali genişlemenin, para arzı genişlemesi ile uyumlaşıtırılmasını gerektirmiştir. Yaşanan tüm bu gelişmeler sonucunda 1980'lerdeki bütçe açığı ve cari açık arasındaki ilişkinin yeterince açı olması, 'ikiz açıklar' kavramının kabul görmesine ve Reagan açıkları olarak yorumlanmasına neden olmuştur (Frankel, 2006; Feldstein, 1992). Bütçe açığından cari açığa uzanan ve 'ikiz açı' olarak adlandırılan sorunla, ABD' nin ardından diğer ülke ekonomileri de tanışmışlardır.

Türkiye ekonomisi açısından bakıldığında, 1980'li yıllarda uygulanan finansal serbestleşme adımları ve neoliberal politikaların ağılık kazanması, ilerleyen yıllarda bütçe açığı ile birlikte cari açığın da artması sonucunu doğurmuştur. Bunlara ek olarak 1997'de yaşanan Güney Asya krizi, 1998 yılında patlak veren Rusya krizi, 1999 yılında meydana gelen büyük deprem ve 2000'li yıllara doğru Arjantin'de ortaya çıkan kriz, gelişmekte olan diğer ülkelerde olduğu gibi sermaye kaçışlarına neden olmuştur (Eğilmez, 2018, s. 74). Yaşanan serbestleşme süreci ve dış etkenler ile artan cari açık ve bütçe açıkları, 1994 ve 2001 krizleri ile daha da ivme kazanmıştır. Ardından dünya ekonomilerinin 2008 krizini yaşamaları, bu konuya olan bakış açısını değiştirmiş ve çözüm arayışları başlamıştır (Bolat, Belke ve Aras, 2011, s. 347-364). 
2008 krizinin ardından, yeniden popüler hale gelen bütçe açıkları ve cari açık sorununun, Türkiye'de de yıllardan beri süregelmesi nedeniyle, kriz sonrası dönem için nedensellik ilişkilerinin varlığının ve yönlerinin araştırılmasının önemli olduğu düşünülmektedir. Bu nedenlerle bütçe açığı ve cari açık arasındaki ilişkinin 2008 krizi sonrası dönem için test edilmesinin literatüre katkı sağlayacağı düşünülmektedir. Bu amaçlarla yapılan çalışmada, giriş bölümünün ardından 'ikiz açıklar teorisi' üzerine yapılan ve çeşitli dönemleri kapsayan araştırmalara ait literatür taramasına yer verilmiştir. Devamında, temel teorik çerçeve kısaca açıklanmıştır. Dördüncü bölümde araştırmada yer alan değişkenlere ait veri seti hakkında bilgiler verilmiş ve hangi ampirik yöntem ile araştırıldığına dair bilgiler sunulmuştur. Son bölümde ise, 2009 yılı ilk çeyrek ve 2020 yılı ikinci çeyrek dönemleri arasında bütçe açıları ve cari açık arasındaki ilişkinin sonuçları tartışılmıştır. Ardından genel bir değerlendirme ile tavsiyelerde bulunulmuştur.

\section{Literatür}

Bütçe açığı ve cari açık değişkenlerinin arasındaki ilişkinin ikiz açık hipotezi çerçevesinde birçok araştırmacı tarafından incelendiği ve halen incelenmekte olduğu görülmektedir. Yapılan çalış̧malarda kısa ve uzun dönem ilişkisi araştırılarak çeşitli yöntem ve metotlar kullanılmıştır. Teoride de varsayıldığı üzere bütçe açığından cari açığa, cari açıktan bütçe açığına, iki değişken için karşılıklı etkileşim ve nedensellik ile son olarak aralarında hiçbir nedensellik olmadığı yönünde sonuçlara ulaşılmıştır. İkiz açık hipotezi ile ilgili olarak literatürde yer alan çalışmalar Tablo 1'de belirtilmiştir.

Tablo 1: İkiz Açık Hipotezi ile İlgili Çalışmalar

\begin{tabular}{|l|c|c|c|c|c|}
\hline Çalışma & $\begin{array}{c}\text { Kullanılan } \\
\text { Yöntem }\end{array}$ & $\begin{array}{c}\text { Zaman } \\
\text { Aralığı }\end{array}$ & Ülke & Periyod & Ulaşılan Sonuç \\
\hline $\begin{array}{l}\text { Utkulu, } \\
\text { (2003) }\end{array}$ & $\begin{array}{c}\text { Eşbütünleşme } \\
\text { ve hata } \\
\text { düzeltme } \\
\text { modeli ile } \\
\text { nedensellik } \\
\text { analizi }\end{array}$ & $\begin{array}{c}1950- \\
2000\end{array}$ & Türkiye & Yıllık & $\begin{array}{c}\text { Uzun dönemde çift } \\
\text { yönlü nedensellik tespit } \\
\text { edilmiştir. Keynesyen teori } \\
\text { desteklenmiştir. }\end{array}$ \\
\hline
\end{tabular}




\begin{tabular}{|c|c|c|c|c|c|}
\hline \begin{tabular}{|l} 
Erdinç, \\
(2008)
\end{tabular} & $\begin{array}{l}\text { Eşbütünleşme } \\
\text { analizi ve } \\
\text { Granger } \\
\text { Nedensellik } \\
\text { testi }\end{array}$ & $\begin{array}{l}1950- \\
2005\end{array}$ & Türkiye & Yillik & $\begin{array}{l}\text { Bütçe açıkları ile cari işlem } \\
\text { açıkları arasında uzun } \\
\text { dönemli bir iliş̧ki olduğu } \\
\text { sonucuna varımıştır. } \\
\text { Geleneksel Keynesyen } \\
\text { Yaklaşım desteklenmektedir. }\end{array}$ \\
\hline $\begin{array}{l}\text { Öruç, } \\
\text { (2017) }\end{array}$ & \begin{tabular}{l|} 
Phillips-Ouliaris \\
eşbütünleşme \\
testi, Dinamik \\
en küçük \\
kareler yöntemi
\end{tabular} & $\begin{array}{l}1975- \\
2015\end{array}$ & Türkiye & Yillık & $\begin{array}{c}\text { Bütçe açıkları ile cari işlemler } \\
\text { açığı arasında uzun dönemli } \\
\text { ilişki tespit edilmiştir. } \\
\text { Ricardocu Denklik Teorisi } \\
\text { reddedilmiştir. }\end{array}$ \\
\hline \begin{tabular}{|l|} 
Mangır, \\
(2012)
\end{tabular} & $\begin{array}{c}\text { Johansen } \\
\text { eşbütünleşme } \\
\text { testi, Granger } \\
\text { nedensellik } \\
\text { analizi } \\
\end{array}$ & $\begin{array}{c}1980- \\
2011\end{array}$ & Türkiye & Yillık & $\begin{array}{l}\text { Bütçe açığından cari açığa } \\
\text { tek yönlü nedensellik } \\
\text { (Granger) ilişkisi tespit } \\
\text { edilmiştir. Keynesyen } \\
\text { yaklaşım desteklenmiştir. }\end{array}$ \\
\hline $\begin{array}{l}\text { Diner ve } \\
\text { Taş (2016) }\end{array}$ & $\begin{array}{l}\text { Johansen Eş } \\
\text { Bütünleşme } \\
\text { Testi, Granger } \\
\text { Nedensellik } \\
\text { testi }\end{array}$ & $\begin{array}{c}1980- \\
2015\end{array}$ & Türkiye & Yillık & $\begin{array}{l}\text { Cari açık değişkeninden } \\
\text { bütçe açığı değişkenine } \\
\text { doğru tek yönlü nedensellik } \\
\text { iliş̧kisi tespit edilmiştir. }\end{array}$ \\
\hline $\begin{array}{l}\text { İyidoğan } \\
\text { ve Erkam, } \\
(2013)\end{array}$ & $\begin{array}{l}\text { Granger } \\
\text { nedensellik } \\
\text { analizi }\end{array}$ & $\begin{array}{l}1987- \\
2005\end{array}$ & Türkiye & Çeyreklik & $\begin{array}{c}\text { Türkiye'de cari açığın bütçe } \\
\text { açığı üzerinde etkili olduğu } \\
\text { sonucuna ulaşıımıştır. İkiz } \\
\text { açık hipotezinin geçerliliği } \\
\text { reddedilmiştir. }\end{array}$ \\
\hline $\begin{array}{l}\text { Yanık, } \\
\text { (2006) }\end{array}$ & $\begin{array}{l}\text { VAR modeli, } \\
\text { Granger } \\
\text { nedensellik } \\
\text { analizi , hata } \\
\text { düzeltme } \\
\text { modeli ve etki- } \\
\text { tepki analizi }\end{array}$ & $\begin{array}{l}1988- \\
2005\end{array}$ & Türkiye & Çeyreklik & $\begin{array}{c}\text { Yapılan ayrıştırma } \\
\text { sonucunda değişkenlerin } \\
\text { normal hareketlerinin tersi } \\
\text { yönde hareket ettikleri } \\
\text { görülmüştür. Uzun } \\
\text { dönemde ise iki değişkenin } \\
\text { birlikte hareket ettikleri tespit } \\
\text { edilmiştir. }\end{array}$ \\
\hline $\begin{array}{l}\text { Mucuk, } \\
\text { (2008) }\end{array}$ & $\begin{array}{l}\text { VAR modeli, } \\
\text { etki-tepki ve } \\
\text { nedensellik } \\
\text { analizi }\end{array}$ & $\begin{array}{l}1989- \\
2004\end{array}$ & Türkiye & Çeyreklik & $\begin{array}{l}\text { Bütçe açığı ile cari açık } \\
\text { arasında karşılıklı bir iliş̧ki } \\
\text { tespit edilmiştir. }\end{array}$ \\
\hline Kör, (2012) & $\begin{array}{l}\text { VAR modeli, } \\
\text { Granger } \\
\text { nedensellik } \\
\text { ve etki-tepki } \\
\text { analizi }\end{array}$ & $\begin{array}{c}1992- \\
2011\end{array}$ & Türkiye & Çeyreklik & $\begin{array}{l}\text { Ricardocu Denklik } \\
\text { Hipotezi'ni destekler } \\
\text { nitelikteki iki değişkenin } \\
\text { de birbirine doğru } \\
\text { nedenselliğinin olmadığı } \\
\text { sonucuna ulaşılmıştır }\end{array}$ \\
\hline $\begin{array}{l}\text { Turan ve } \\
\text { Karakaş, } \\
\text { (2017) }\end{array}$ & NARDL analizi & $\begin{array}{c}1998- \\
2016\end{array}$ & Türkiye & Çeyreklik & $\begin{array}{c}\text { Türkiye'de ikiz açık } \\
\text { hipotezinin desteklenmediği } \\
\text { belirtilmiştir }\end{array}$ \\
\hline
\end{tabular}




\begin{tabular}{|c|c|c|c|c|c|}
\hline $\begin{array}{l}\text { Altunöz, } \\
\text { (2014) }\end{array}$ & $\begin{array}{l}\text { ARDL sınır testi } \\
\text { analizi }\end{array}$ & $\begin{array}{l}2000- \\
2013\end{array}$ & Türkiye & Çeyreklik & $\begin{array}{l}\text { Uzun dönemli bir ilişki söz } \\
\text { konusu değil iken, kısa } \\
\text { dönemde pozitif ve güçlü } \\
\text { bir ilişki tespit edilmiştir. } \\
\text { Kısa dönemde Keynesyen } \\
\text { yaklaşım geçerli iken, uzun } \\
\text { dönemde Ricardocu Denklik } \\
\text { Hipotezi desteklenmiştir. }\end{array}$ \\
\hline $\begin{array}{l}\text { Kılavuz ve } \\
\text { Dumrul, } \\
\text { (2012) }\end{array}$ & $\begin{array}{l}\text { VAR modeli } \\
\text { ve Granger } \\
\text { nedensellik } \\
\text { analizi }\end{array}$ & $\begin{array}{c}2006- \\
2010\end{array}$ & Türkiye & Aylık & $\begin{array}{c}\text { Uzun dönemde iki } \\
\text { değişken arasında bir ilişki } \\
\text { bulunamamıştır. Ancak } \\
\text { kısa dönemde değişkenler } \\
\text { arasında karşılıklı bir ilişsinin } \\
\text { varlığı tespit edilmiştir. }\end{array}$ \\
\hline \begin{tabular}{|l|} 
Kim ve \\
Kim, (2006)
\end{tabular} & $\begin{array}{c}\text { Toda- } \\
\text { Yamamato } \\
\text { analizi ve Wald } \\
\text { testi }\end{array}$ & $\begin{array}{l}1970- \\
2003\end{array}$ & Kore & Yillık & $\begin{array}{l}\text { Kore'de yüksek bütçe } \\
\text { açıklarının daha büyük cari } \\
\text { açıklara neden olmadığı, } \\
\text { aksine cari açıktan bütçe } \\
\text { açıklarına doğru tek yönlü } \\
\text { bir nedensellik ilişkisinin } \\
\text { olduğu tespit edilmiştir. }\end{array}$ \\
\hline \begin{tabular}{|l|} 
Marinheiro, \\
$(2008)$
\end{tabular} & $\begin{array}{c}\text { Granger } \\
\text { nedensellik } \\
\text { analizi } \\
\end{array}$ & $\begin{array}{l}1974- \\
2002\end{array}$ & MIsır & - & $\begin{array}{l}\text { Bütçe açığı ve cari açık } \\
\text { arasında uzun dönemli zayıf } \\
\text { bir iliş̧i tespit edilmiştir. }\end{array}$ \\
\hline $\begin{array}{l}\text { Bilgili ve } \\
\text { Bilgili, } \\
\text { (1998) } \\
\end{array}$ & $\begin{array}{c}\text { Regresyon } \\
\text { analizi }\end{array}$ & $\begin{array}{l}1975- \\
1993\end{array}$ & $\begin{array}{l}\text { Türkiye, } \\
\text { Singapur ve } \\
\text { ABD }\end{array}$ & - & $\begin{array}{l}\text { Ricardocu Denklik } \\
\text { Hipotezi'nin geçerli olduğu } \\
\text { ortaya konulmuştur. }\end{array}$ \\
\hline \begin{tabular}{|l|} 
Ahmed ve \\
Akın, (2019)
\end{tabular} & $\begin{array}{c}\text { Engle-Granger } \\
\text { modeli, } \\
\text { Granger } \\
\text { nedensellik } \\
\text { analizi ve Toda } \\
\text { and Yamamoto } \\
\text { nedensellik testi }\end{array}$ & $\begin{array}{c}1990- \\
2014\end{array}$ & Yemen & Yillık & $\begin{array}{c}\text { Cari işlemlerden bütçe } \\
\text { açığına doğru pozitif } \\
\text { yönlü bir nedensellik iliş̧ki } \\
\text { tespit edilmiştir. ikiz açık } \\
\text { hipotezinin geçerliliği kabul } \\
\text { edilmiştir. }\end{array}$ \\
\hline $\begin{array}{l}\text { Barışık ve } \\
\text { Kesikoğlu, } \\
(2010)\end{array}$ & $\begin{array}{l}\text { Panel veri } \\
\text { analizi }\end{array}$ & $\begin{array}{l}1991- \\
2007\end{array}$ & $\begin{array}{c}\text { Güney } \\
\text { Afrika, Çin, } \\
\text { Endonezya, } \\
\text { Hindistan, } \\
\text { İsrail, } \\
\text { Kolombiya, } \\
\text { Macaristan, } \\
\text { Meksika, } \\
\text { Mısır, Peru, } \\
\text { Tayland ve } \\
\text { Türkiye }\end{array}$ & Yillık & $\begin{array}{c}\text { Bütçe açığı ile cari açık } \\
\text { arasında çift yönlü } \\
\text { bir nedensellik ilişkisi } \\
\text { bulunmuştur. Geleneksel } \\
\text { Keynesyen Hipotezi } \\
\text { destekleyen sonuçlar tespit } \\
\text { edilmiştir. }\end{array}$ \\
\hline
\end{tabular}




\begin{tabular}{|c|c|c|c|c|c|}
\hline $\begin{array}{l}\text { Sinicakova, } \\
\text { Sulikova ve } \\
\text { Gavurova, } \\
\text { (2017) }\end{array}$ & $\begin{array}{c}\text { Granger } \\
\text { nedensellik } \\
\text { analizi }\end{array}$ & $\begin{array}{c}2000- \\
2014\end{array}$ & $\begin{array}{c}28 \text { Avrupa } \\
\text { Birliği ülkesi }\end{array}$ & Yillık & $\begin{array}{c}\text { İspanya ve Macaristan } \\
\text { için karşılıklı nedensellik } \\
\text { tespit edilirken; Hollanda, } \\
\text { Yunanistan, Italya, } \\
\text { Portekiz, Güney Kıbrıs, Çek } \\
\text { Cumhuriyeti ve Hırvatistan } \\
\text { için bütçe açığından cari } \\
\text { açığa; Belçika, Finlandiya, } \\
\text { Fransa, İrlanda, Malta ve } \\
\text { Romanya için cari açıktan } \\
\text { bütçe açığına doğru } \\
\text { bir nedensellik ilişkisine } \\
\text { ulaşılmıștır. }\end{array}$ \\
\hline
\end{tabular}

Tablo 1'den görüldüğü üzere ikiz açık hipotezi ile ilgili olarak hem Türkiye'de hem de dünyada araştırmalar devam etmektedir. Yapılan araştırmalarda kullanılan verilerin genellikle yıllık veya çeyreklik dönemler itibariyle analizlere dahil edilmesi, bu çalışmanın zaman serileri tercihinin uygun olduğunu göstermektedir.

Türkiye ekonomisi için yapılan çalışmalardan Utkulu (2003), Erdinç (2008), Mangır (2012) ve Öruç (2017), elde ettikleri bulgularla Keynesyen teoriyi destekler nitelikte sonuçlara ulaşmışlardır. Altunöz (2014) de kısa dönemde Keynesyen teoriyi desteklerken, Kılavuz ve Dumrul (2012) kısa dönemde karşılıklı bir nedensellik tespit etmiş̧ir. Mucuk (2009) da iki değişken arasında karşıllkıı bir nedensellik sonucuna ulaşırken, Yanık (2006), iki değişkenin birlikte hareket ettikleri şeklinde bir bulgu elde etmiştir. Kör (2012) ise yaptığı çalışma ile iki değişkenin birbirine doğru nedenselliğinin olmadığı varsayımı altındaki Ricardocu Denklik hipotezini desteklemektedir. Ricardocu Denklik hipotezini, uzun dönem sonuçları ile destekleyen bir başka çalışma ise Altunöz (2014)'ün çalışmasıdır. Türkiye için yapılan çalışmalarda ikiz açık hipotezinin geçerliliğini reddeden çalışmalar ise, lyidoğan ve Erkam (2013) ve Turan ve Karakaş (2017)'tır.

Kim ve Kim (2006)'in Kore ekonomisi üzerine yaptıkları çalışma ile Sinicakova, Sulikova ve Gavurova (2017)'nın Belçika, Finlandiya, Fransa, İrlanda, Malta ve Romanya ekonomileri için ulaştıkları sonuçlar, cari açıktan bütçe açıklarına doğru tek yönlü bir nedensellik şeklindedir. Ahmed ve Akın (2019) ise Yemen ekonomisi için yapmış oldukları çalışmada ters nedensellik ilişkisi tespit edilmiştir. Bilgili ve Bilgili (1998), Türkiye, Singapur ve ABD ekonomileri için Ricardocu Denklik 
hipotezinin geçerli olduğunu ortaya koymuştur. Barışık ve Kesikoğlu (2010) ise Güney Afrika, Çin, Endonezya, Hindistan, İsrail, Kolombiya, Macaristan, Meksika, Mısır, Peru, Tayland ve Türkiye ekonomileri için yapmış oldukları çalışmada, bütçe açığı ile cari açık arasında çift yönlü bir nedensellik ilişkisi bulunduğu yönünde yani Geleneksel Keynesyen Hipotezi destekleyen sonuçlar elde etmişlerdir. Sinicakova, Sulikova ve Gavurova (2017) da yapmış oldukları çalışmada Hollanda, Yunanistan, İtalya, Portekiz, Güney Kıbrıs, Çek Cumhuriyeti ve Hırvatistan ekonomileri için bütçe açığından cari açığa doğru bir nedensellik tespit ederken, İspanya ve Macaristan için karşılıklı nedensellik ilişkisini ortaya koymuştur.

\section{Teorik Yaklaşımlar}

\subsection{Keynesyen Teori (Geleneksel Teori)}

Keynes'in ikiz açık teorisi Ricardocu denkliğe karşı en güçlü argüman olarak öne sürülmüştür. Bu argüman, cari açık ve bütçe açılları arasında pozitif bir ilişki olduğunu savunmaktadır. İkiz açık hipotezi, bütçe açığının cari açığa yol açacağını ve bütçe fazlasının, cari açığı iyileştireceğini savunmaktadır (Alkswani, 2000, s.1-25).

Keynesyen yaklaşım için ilk olarak gelir-harcama akımında bir genişleme sonucunda meydana gelen cari dengenin bozulması ele alınmıştır. Gelir-harcama hipotezi dikkate alındığında devletin herhangi bir yolla uygulayacağı genişleyici bir maliye politikasının bütçe açıklarını arttıracağı savunulmaktadır. Keynesyen düşünceye göre uygulanan genişleyici maliye politikası ile ekonomik birimlerin gelirlerinde artış meydana gelecektir. Bu artış sebebiyle tüketimlerinde de artış olacaktır. Talep artışının karşılanabilmesi için ise üretim faaliyetlerinin artışı gerçekleşecektir. Böylece hem milli gelirde meydana gelen artış hem de üretimin ithalat ile bağlantılı olduğu düşünüldüğünde, cari açık bu akış içerisinde yukarı yönlü bir ivme gösterecektir (Üzümcü ve Kanca, 2013, s.19).

Dışa açık bir ülke modeli ile bir adım ileri gidildiğinde ise bu kez Mundell Fleming'in IS-LM modeli çerçevesinde bütçe açığı ve cari açı ilişkisi incelenmiştir. Dışa açık bir ekonomide bütçe açığının bir sonucu olarak borçlanma yoluna giden 
hükümet, önceki duruma göre bu borcu daha zor şartlarda ödeyecek ve daha yüksek faiz oranları ile karşı karşıya kalacaktır. Yükselen faiz oranları, yabancı sermaye açısından ise bir fırsat niteliğinde olacaktır. Yurt dışındaki faizlerin sabit olduğu varsayımı altında, yabancı yatırımcı yüksek faizi tercih edecektir. Ancak yüksek faizi görerek gelen yabancı sermaye, yabancı paranın bollaşmasına ve değerinin düşmesine neden olacaktır. Bu da, yerli paranın değer kazanması ile birlikte ihracatı pahalı hale getirecektir. Yerli paranın, dış ticaret yapılan ülke paraları karşııında değerlenmesi bu kez ithalatı teşvik edecektir. İhracat miktarının azalırken ithalatın artması, iki değişen arasındaki makasın açılması sonucunu doğuracaktır. Bu da hem bütçe dengesinin hem de cari dengenin birlikte kötüleşmesi anlamına geldiğinden, bu iki ekonomik değişken arasında bir pozitif ilişki oluşmasına neden olacaktır. Sonuç olarak, bütçe açığında meydana gelen bir artış, ardından cari açığı da arttıracaktır (Mankiw, 2017, s. 120-140).

\subsection{Ricardocu Denklik Hipotezi}

Barro yapmış olduğu çalışmada, belirli miktarlarda yapılacak olan kamu harcamalarının finansmanı için göreceli olarak alınan vergilerin ve yapılacak borçlanmanın etkilerinin toplam talebi, faiz oranlarını ve sermaye oluşumunu hiçbir şekilde etkilemeyeceğini belirtmiştir. Bu görüşlerini, temellerini Ricardo'ya dayandırarak oluşturduğu bir teori ile açık bir şekilde dile getirmiştir. Ricardocu Denklik Hipotezi'ne göre, yetkili otoritenin vergileri düşürmesi veya borçlanma yoluna gitmesi, bireylerin tasarruflarını arttırıcı yönde etki yapacaktır. Çünkü bireyler rasyoneldir. Cari dönemde yapılan vergi indirimlerinin gelecekte vergi artışı olarak döneceğinin farkındadırlar. Bu nedenle de tüketim harcaması yapmak yerine tasarruf yapmayı tercih edeceklerdir (Barro, 1974, s.1095-1117).

Ülkelerin toplam tasarruf yapısı, kamu tasarrufları ve özel tasarrufların toplamından oluşmaktadır. Kamu tasarruflarında bir azalma meydana geldiğinde, özel tasarruflar aynı miktarda artış sağlayacağı için ulusal tasarrufta bir değiş̧iklik olmayacaktır. Kapalı bir ekonomi varsayımı altında planlanan tasarruflarda bir değişiklik olmaması, yatırım-tasarruf eşitliğinin sağlanması için faiz değişikliğine gidilmesini gerektirmeyecektir. Açık bir ekonomide ise özel tasarruflardaki artış 
nedeniyle dış borçlanmaya gerek kalmayacaktır. Sonuç olarak her iki durumda da bütçe açığı cari açığa neden olmayacaktır (Barro, 1989, s. 37-54).

Ricardocu Denklik Hipotezi, Keynesyen teorinin savunduğu, bireylerin rasyonel davranmayacakları ve ulusal tasarrufların azalmasının faizler üzerinde bir etki yaratmaması durumlarını reddetmiştir. Aksine 'Rasyonel Bekleyişler Teorisi'ni de baz alarak, bireylerin gelecekteki vergi artışlarını hesaba katacaklarını öne sürmüştür. Bu davranışlarının sonucunda da özel tasarruflarını arttıracaklarından, kamu tasarruflarındaki azalmanın dengeleneceği belirtilmiştir. Sonuç olarak bütçe açığında meydana gelen artış, faiz oranlarında herhangi bir etki yaratmayacağından cari açık ile arasında herhangi bir ilişki de olmayacaktır. İki değişken arasında ilişki olduğunu öne süren Keynesyen teorinin aksine ikiz açık hipotezinin geçerliliği reddedilmektedir.

\subsection{Cari İşlemler Hedeflemesi}

Bir diğer yaklaşım ise, belirli durumlarda nedenselliğin cari açıtan bütçe açığına doğru akıp gitmekte olabileceği yaklaşımıdır. Burada tek yönlü bir nedensellikten bahsedilmekte ve Keynesyen teorinin aksine cari açıktan bütçe açığına doğru bir durumdan söz edilmektedir. Yani tam tersi bir durum söz konusudur. Cari işlemler hesabında meydana gelen bozulmanın ekonomik büyümeyi yavaşlatacağı ve dolayısıyla bütçe açığını arttıracağı savunulmaktadır. Bu durum özellikle ekonomik gelişmelerini finanse etmek için yabancı sermaye girişlerine bağlı olan küçük, açık ve gelişmekte olan ülke ekonomileri için geçerlidir. Başka bir deyişle, bir ülkenin bütçe dengesi, büyük sermaye girişlerinden veya borç birikimlerinden etkilenecek ve bunun sonucunda bütçe açığı ile karşı karşıya kalacaktır (Bakarr, 2014, s. 258).

Küçük, dışa açık ve gelişmekte olan bir ülkenin sermaye akışını, gelişmiş ülkeler kadar kontrol edememesi veya gelişmiş ülkelerin tavrı karşısında dış dengeyi koruma önlemlerinin yetersiz kalması, daha yüksek cari hesap dengesizliği ve sermaye hareketlerine neden olabilecektir. Bu durum reel döviz kurunda hareketlilik yaşanmasına neden olacaktır. Summers (1988, s. 349-386) yapmış olduğu 
çalışmasında, sermayenin uluslararası olarak hareketli olduğunu, ancak hükümetlerin cari açık sorunu nedeniyle yalnızca nispeten küçük sermaye akışlarına izin verecek şekilde hareket ettiklerini belirtmiştir. Yani, büyük bir sermaye akışının gerçekleşmesi ülkedeki borçların birikmesine ve dolaylı olarak bütçede açık yaratmasına neden olmaktadır. Ülkelerin büyük sermaye girişlerini istememelerinin temel sebebi budur. Çünkü aksi bir durum gerçekleştiğinde cari işlemler dengesinde oluşacak açığın kapatılması için dış borçlanma seçeneği kullanılacaktır.

Gelişmekte olan ülkelerin ekonomik büyümesi için yabancı sermaye girişi oldukça önemlidir. Ancak beklenen yabancı sermaye gelmediğinde, dış borçlanmaya gidilerek ülkelere bu yolla döviz girişi sağlanmaktadır. Bu şekilde veya yabancı sermaye yoluyla sağlanan döviz girişinin doğru yerlerde kullanılması oldukça önemlidir. Aksi takdirde aynı sorun artarak devam edecek ve tekrar dış borçlanma ihtiyacı doğacaktır. Bu durum ise faizlerde yukarı yönlü bir harekete sebep olacak ve önce ülke parasının değeri artacak ardından da ihracat yavaşlayacaktır. Böylece ihracattan sağlanan döviz girişi de azalarak önce cari açığı ardından da büyümenin yavaşlaması ile bütçe açığına neden olacaktır.

Büyüme hızındaki yavaşlamanın bütçe açığına etkisini açıklamak için ithal girdinin önemine vurgu yapılmıştır. Ekonomik büyüme için ithal girdi kullanımı yüksek olan ülkeler ithalatın kısılması yoluna gittiklerinde, girdi kullanımının azlığı ile birlikte üretim ve ardından tüketimde yavaşlama görülecektir. Bu aktarım mekanizmasının sonucunda büyüme hızında yavaşlama yaşanacaktır. Büyüme hızında meydana gelen bu yavaşlama ise, vergi gelirlerini azaltarak, kamu harcamalarının arttıııması sonucunu doğuracaktır. Böylece bütçe açığı giderek artan bir hal alacaktır. Yani cari açık hedeflemesi stratejisi ile azaltılan ithalat kalemi sonuç olarak bütçe açığının artmasına neden olacaktır (Ahmed ve Akın, 2019, s. 118-119).

\section{Ekonometrik Analiz}

\subsection{Model ve Veri Seti}

Bu çalışmada, ikiz açık teorisi çerçevesinde ters nedensellik durumunun Türkiye ekonomisinde varlığı araştııılmıştır. Yapılan araştırmada kullanılan cari açık ve bütçe 
açığı değişkenleri, ekonometrik model ile analiz edilerek, Türkiye ekonomisi için sonuçlara ulaşılmaya çalışılmışıtr. Illgili model için herhangi bir yapısal kırılmanın olmaması ve 2008 finansal krizi sonrası dönemi içermesi açısından 2009 yılı başlangıç yılı olarak seçilmiştir. Bu nedenlerle 2009:1Q ve 2020:2Q dönemleri arası çeyreklik veriler kullanılmıştır. Öruç (2017), Altunöz (2014), Kılavuz ve Dumrul (2012)'un farklı periyodlarda yapmış oldukları çalışmalara bakıldığında, incelenen dönem için modele dahil edilen gözlem sayısının oldukça yeterli olduğu anlaşılmaktadır.

Literatürde yer alan benzer çalışmalarda bütçe açığı verisine ilişkin birçok değişkenin sınandığı görülmüştür. Bu nedenle çalışmada yer alan bütçe açığı verisi için Genel Bütçe Dengesi'nin GSYIH'ya oranı baz alınmıştır. Yine bir diğer ölçüt olan cari açık verisi için ise Cari İşlemler Dengesi GSYIH'ya oranlanarak modele dahil edilmiştir. Genel Bütçe Dengesi'nin GSYiH'ya oranı bağımlı değişken olarak, Cari İşlemler Dengesi 'nin GSYIH'ya oranı ise bağımsız değişken olarak belirlenmiştir. Her iki değişken için Türkiye Cumhuriyet Merkez Bankası'nın resmi sitesinde yer alan elektronik veri tabanından (EVDS) yararlanılmışır. Cari açık verisi dolar bazlı elde edildiğinden, bu veri EVDS'den çeyreklik olarak alınan kur değerleri ile Türk Lirası'na çevrilmiş ve kullanılan seriler ARDL (Autoregressive Distibuted Lag, Gecikmesi Dağıtılmış Otoregresif Model) analizi öncesinde mevsimsellik etkisinden arındırılmıştır. Mevsimsellikten arındırma işleminde STL (Seasonal and Trend decomposition using Loess) yöntemi kullanılmış ve değişkenlerin mevsimsel etkiden arındırılmış olduğu (_SA) kodu ile ifade edilmiştir. Modelde kullanılan serilere ilişkin semboller Tablo 2'de gösterilmiştir.

Tablo 2: Modelde Kullanılan Veriler ve Semboller

\begin{tabular}{|l|c|}
\hline Verinin Adı ve Açıklaması & Kısaltması \\
\hline Bütçe Dengesi/ GSYiH (2009-2020) & GBA_SA \\
\hline Cari İşlemler Dengesi /GSYiH (2009-2020) & CA_SA \\
\hline
\end{tabular}

\subsection{Metodoloji}

Zaman serileri şeklinde derlenen Bütçe Dengesi/ GSYIH (2009-2020) ve Cari İşlemler Dengesi /GSYIH (2009-2020) verilerine eşbütünleşme analizi ve 
Gecikmesi Dağıtılmış Otoregresif (ARDL) sınır testleri uygulanmıştır. Yapılan bu uygulamalar için Pesaran, Shin ve Smith (2001, s. 289-326)'nin kapsamlı çalışmalarından yararlanılmışır. Illk olarak veri setinin durağanlığına (stationary) bakılmış, bu çalışma için en uygun olduğu düşünülen Genişletilmiş Dickey-Fuller (Augmented Dickey-Fuller (ADF) birim kök testi kullanılmıştır (Dickey ve Fuller, 1981, s. 1057-1072). Illgili seriler durağan hale getirildikten sonra, uygun gecikme uzunlukları tespit edilmiştir. Gecikme uzunluklarının tespiti için ARDL modelinin seçim kriterlerinden yararlanılmışıı. Gecikme uzunlukları belirlendikten sonra model ARDL sınır testi ile tahmin edilerek, eşbütünleşme ilişkisi analiz edilmiştir. Analizin son kısmında, Hata Düzeltme Modeli (ECM) ile değişkenler arasındaki nedenselliğin yönü belirlenmeye çalışılmıştır. Verilere ait yapılan tüm kısa ve uzun dönem nedensellik analizleri EViews 10.0 programı aracılı̆̆ıyla tespit edilmeye çalışılmıştır.

\subsection{Analiz}

Eviews programında alternatifleri de olan birim kök testleri ile serilerin durağanlıkları sınanmaktadır. Bu testler aracılığıyla kullanılan serilerin ne düzeyde durağan oldukları veya hangi düzeyde durağan hale geldikleri araştırılmaktadır. Analize dahil edilen verilerin durağan olmasının anlamı ise, ortaya çıkabilecek ani bir ekonomik hareketin veya şokun etkisinin uzun sürmeyeceği yönünde bilgi vermesidir. Ancak seriler beklendiği gibi durağan değilse meydana gelen dalgalanma sürecinin ardından dengeyi çabuk bulamayacağı öngörülmektedir (Barışık ve Demircioğlu, 2012, s. 74).

ARDL sınır testi yapmadan önce kurulacak modelde sahte regresyon sorunu oluşmaması adına modelde yer alan bütçe açığı ve cari açık değişkenlerinin durağan olup olmadıkları tespit edilmiştir. Kullanılan analiz yöntemi nedeniyle değişkenlerin I(1) fark veya I(0) düzeyde olması gerekmektedir. I(2) fark veya daha yüksek derecede olmadıklarının netleştirilmesi için ADF (Augmented Dickey Fuller) ve PP (Phillips Perron) birim kök testlerinden yararlanılmışır (Çağlayan, 2006, s.427). Çalışmaya ait serilerin durağanlık sonuçlarının detayları Tablo 3'de gösterilmiştir. 
Tablo 3: Durağanlık Test Sonuçları

\begin{tabular}{|c|c|c|c|c|}
\hline & \multicolumn{2}{|c|}{ ADF } & \multicolumn{2}{|c|}{ PP } \\
\hline & $I(0)$ & $\mathrm{I}(1)$ & $I(0)$ & $\mathrm{I}(1)$ \\
\hline \multicolumn{5}{|l|}{ Sabitli } \\
\hline CA_SA & $-1,632$ & $-7,814^{\star}$ & $-2,790 * * *$ & $-9,258^{*}$ \\
\hline GBA_SA & $-5,024^{*}$ & $-8,229 *$ & $-6,721^{*}$ & $-15,260$ \\
\hline \multicolumn{5}{|c|}{ Sabitli ve Trendli } \\
\hline CA_SA & $-4,289 *$ & $-7,852^{\star}$ & $-3,184$ & $-9,665^{\star}$ \\
\hline GBA_SA & $-4,928 *$ & $-6,473^{*}$ & $-6,547^{\star}$ & $-21,305^{*}$ \\
\hline
\end{tabular}

Not: Durağanlık sınamasında ADF birim kök testi için Schwartz Bilgi Kriteri, PP birim kök testi için Bartlett Kernel tahmin

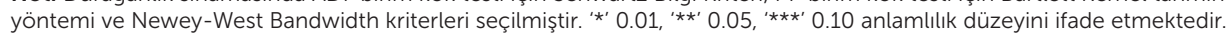

Tablo 3'te görüldüğü üzere yapılan birim kök testi sonuçlarına göre seriler farklı dereceden durağandır. Hem kısa dönem hem de uzun dönem analizi yapmaya olanak sağlayan ARDL modeli I(0), I(1) ya da her ikisinin birleşimi şeklinde yani farklı derecede eş bütünleşik seriler için kullanıma izin vermektedir (Nkoro ve Uko, 2016, s. 63-91). Yapılan durağanlık testleri ile boş hipotez \%1 anlamlılık düzeyinde reddedilmektedir. Ulaşılan sonuç, her iki değişkene ait olan serinin de \%1 anlamlılık düzeyinde durağan olduğunu göstermektedir.

\section{Şekil 1. Bütçe Açığı ve Cari Açık Serilerinin Durağanlıkları}
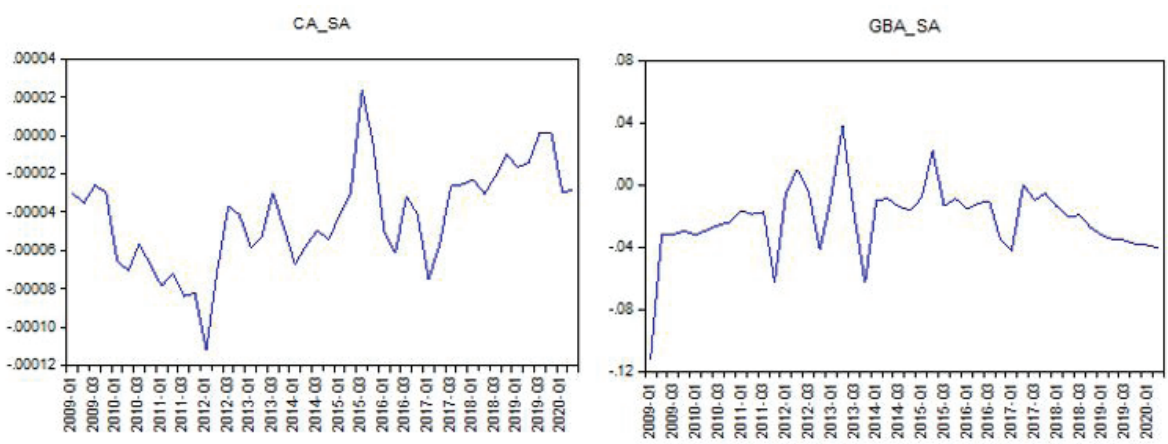

Şekil 1'de de görüldüğü üzere en uygun modelin tespit edilmesi için değişkenlerin grafiklerine de bakılmıştır. Tüm birim kök sınamaları yapıldıktan sonra teste başlamak için ilk aşama olan gecikme uzunluklarının belirlenmesi işlemi gerçekleştirilmiştir. En uygun gecikme uzunluğunun bulunabilmesi için aşağıdaki 
tabloda yer alan LogL, Akaike bilgi kriteri (AIC), Bayes bilgi kriteri (BIC), HannanQuinn bilgi kriteri (HQ) ve R-kare ölçütü kriterlerinden yararlanılmıştır. Tablo 4'te görüldüğüüzere, Akaike (AIC) bilgi kriteri çerçevesinde en düşük değer dikkate alınarak, en uygun gecikme uzunluğunun 5 olduğu tespit edilmiştir.

Tablo 4: Gecikme Uzunluklarının Belirlenmesi

\begin{tabular}{|l|c|c|c|c|c|c|}
\hline Model & LogL & AIC* & BIC & HQ & Adj. R-sq & Specification \\
\hline $\mathbf{1}$ & $\mathbf{1 1 4 , 0 4 1 8 2 5}$ & $-\mathbf{5 , 1 7 2 7 7 2}$ & $-\mathbf{4 , 8 3 8 4 1 6}$ & $-\mathbf{5 , 0 5 1 0 1 8}$ & $\mathbf{0 , 2 5 9 3 2 3}$ & ARDL(1, 5) \\
\hline 2 & 112,040445 & $-5,123924$ & $-4,831363$ & $-5,017390$ & 0,207384 & ARDL(1, 4) \\
\hline 5 & 107,042614 & $-5,026469$ & $-4,859291$ & $-4,965592$ & 0,070563 & ARDL(1, 1) \\
\hline 6 & 105,335666 & $-4,991984$ & $-4,866600$ & $-4,946326$ & 0,016443 & ARDL(1, 0) \\
\hline 4 & 107,211126 & $-4,985909$ & $-4,776936$ & $-4,909812$ & 0,052566 & ARDL(1, 2) \\
\hline 3 & 107,211194 & $-4,937131$ & $-4,686365$ & $-4,845816$ & 0,025500 & ARDL(1, 3) \\
\hline
\end{tabular}

Tablo 4'te gösterildiği şekilde en uygun gecikme uzunluğu belirlenmiş ve buna göre uygulanacak modelin $(1,5)$ olduğu görülmüştür. Ardından ARDL testinin uygulanabilmesi ve analize dahil edilen değişkenler arasında uzun dönemli bir istatistiksel ilişki olup olmadığının tespit edilmesi amacıyla $F$ istatistik değerinin belirlenmesi gerekmektedir.

Hipotezler:

$\mathrm{H}_{0}$ : Cari Açık ve Bütçe Açığı serileri eş bütünleşik değildir. (I)

$\mathrm{H}_{1}$ : Cari Açık ve Bütçe Açığı serileri eş bütünleşiktir. (II)

Tablo 5: Sınır Testi ve Eşbütünleşme Sonuçları

\begin{tabular}{|l|c|c|c|c|}
\hline Test İstatistiği & Değer & Seviye & $\mathbf{I}(\mathbf{0})$ & $\mathbf{I}(\mathbf{1})$ \\
\hline F-İstatistiği & $\mathbf{1 0 , 2 4 3 2 8}$ & $10 \%$ & 3,02 & 3,51 \\
\hline$k$ & 1 & $5 \%$ & 3,62 & 4,16 \\
\hline & & $2,5 \%$ & 4,18 & 4,79 \\
\hline & & $1 \%$ & 4,94 & 5,58 \\
\hline
\end{tabular}

Not: Kritik değerler Eviews 10 paket programı ile yapılan "Bound Test" sonucu belirlenmiştir. k ifadesi kaç değişken olduğunu göstermektedir.

Tablo 5'te yer alan test sonuçları, \%5 anlamlılık düzeyine göre hesaplanan $\mathrm{F}$ istatistik değerinin (10.24328), kritik de er olan I(0) ve I(1) üst düzeyinden daha büyük olduğunu göstermektedir. Buna göre seride eş bütünleşme olmadığına dair 
kurulan $\mathrm{H}_{0}$ hipotezinin bu test sonucuna göre de reddedilip, seriler arasında her anlamlılık düzeyinde eşbütünleşme bulunduğu söylenebilecektir.

Değişkenler arası eşbütünleşme ilişkisi tespit edildikten sonra değişkenler arasındaki uzun dönemli ilişki ARDL sınır testi ile tahmin edilmiştir. ARDL sınır testi ile birçok analiz yapılabilmesinin yanında veri sayısının daha sınırlı olduğu çalışmalarda uygulanabilir olması oldukça avantaj yaratan bir durumdur. Bu çalışmalarda Engle Granger ve Johansen eşbütünleşme testlerine kıyaslandığında daha güvenli ve kaliteli sonuçlar verdiği tespit edilmiştir (Narayan ve Smyth, 2005, s. 103). Çalışmamızda gözlem sayısının sınırlı olması ARDL sınır testi ile yapılan analizin daha güvenilir sonuçlar vereceği sonucunu doğurmaktadır. Yapılan test sonuçları Tablo 6'da gösterilmiştir.

Tablo 6: ARDL $(1,5)$ Modelinin Uzun Dönem Sonuçları

\begin{tabular}{|c|c|c|c|}
\hline \multicolumn{4}{|c|}{ (Bağımlı Değişken: D(GBA_SA) } \\
\hline Değişkenler & Katsayı & t-istatistiği & Olasılık \\
\hline C & $-0,035630$ & $-4,392731$ & 0,0001 \\
\hline GBA_SA(-1)* & $-0,981153$ & $-5,207656$ & 0,0000 \\
\hline CA_SA(-1) & $-370,5705$ & $-2,660065$ & 0,0120 \\
\hline $\mathrm{D}\left(\mathrm{CA} \_\mathrm{SA}\right)$ & 115,4730 & 0,637671 & 0,5281 \\
\hline D(CA_SA(-1)) & 340,2193 & 1,816400 & 0,0784 \\
\hline D(CA_SA(-2)) & 237,2078 & 1,260853 & 0,2162 \\
\hline D(CA_SA(-3)) & 515,9930 & 3,292320 & 0,0024 \\
\hline D(CA_SA(-4)) & 321,1285 & 1,839632 & 0,0748 \\
\hline \multicolumn{4}{|c|}{ Uzun Dönem Katsayılar } \\
\hline Değişkenler & Katsayı & t-istatistiği & Olasılık \\
\hline CA_SA & $-377,6889$ & $-2,527780$ & 0,0164 \\
\hline C & $-0,036314$ & $-5,028607$ & 0,0000 \\
\hline Diagnotik Testler & \multicolumn{3}{|c|}{ İstatistiksel Sonuçlar } \\
\hline R kare & \multicolumn{3}{|c|}{0,388942} \\
\hline Düzeltilmiş $\mathrm{R}$ kare & \multicolumn{3}{|c|}{0,259323} \\
\hline F İstatistiği & \multicolumn{3}{|c|}{$3,000669(0,014938)$} \\
\hline Durbin Watson istatistiği & \multicolumn{3}{|c|}{1,885466} \\
\hline Breusch-Godfrey LM test istatistiği & \multicolumn{3}{|c|}{$1,118175(0,3397)$} \\
\hline Jarque-Bera & \multicolumn{3}{|c|}{$4,956944(0,083871)$} \\
\hline Ramsey Reset test istatistiği & \multicolumn{3}{|c|}{$4,335877(0,0454)$} \\
\hline White test istatistiği & \multicolumn{3}{|c|}{$36,89050(0,3815)$} \\
\hline
\end{tabular}

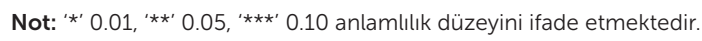


Tablo 6'da yer alan uzun dönem sonuçlarına göre, iki değişken arasında anlamlı ancak negatif bir ilişki söz konusudur. Yani, diğer koşullar sabitken cari açıkta meydana gelen değişme, bütçe açığında azalışa neden olacaktır. Uzun dönem test sonuçlarına istinaden modelde herhangi bir otokorelasyon (Breusch-Godfrey LM Testi) ve değişen varyans (White Testi) sorununun bulunmadığı görülmektedir. Hata teriminin de normal dağıldı̆̆ı (Jarque-Bera Normallik Testi) ve model kurma hatasının (Ramsey Reset Testi) olmadığı anlaşılmaktadır.

Modelin tamamlayıcı testleri ve uzun dönem sonuçları yorumlandıktan sonra parametrelerin kararlılığı CUSUM ve CUSUMQ testleri ile tespit edilmiştir. Bu testler, ARDL modeli gibi zaman serisi ve resgresyon analizlerinde yer alan değişkenlerin istikrarlı olup olmadığını ve tahminleri yapılan değişkenlerde yapısal kırılmanın varlığı konusunda bilgi vermektedir (Brown, Durbin ve Evans, 1975, s. 149-163). Yapılan kararlılık testleri Şekil 2'de sunulmuştur.

\section{Şekil 2. Cusum ve Cusum Square Testleri}
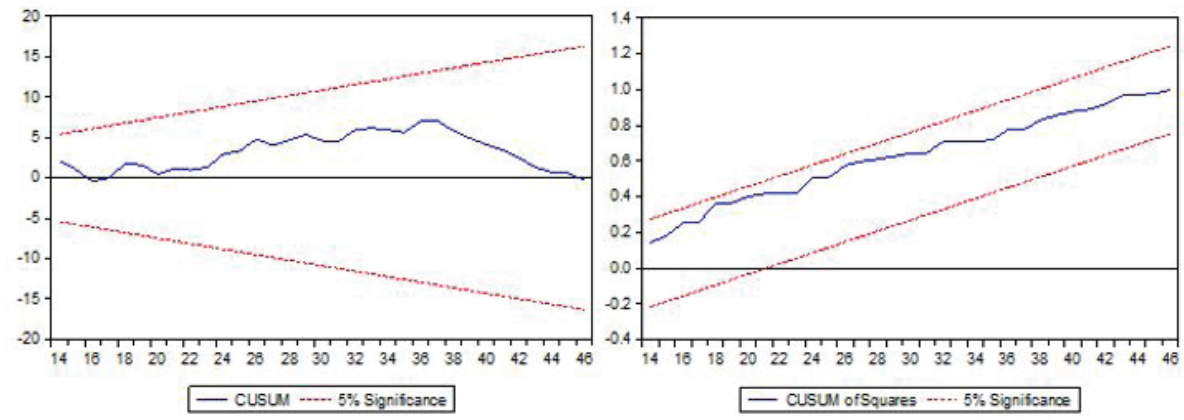

Şekil 2'de yer alan CUSUM ve CUSUMQ testleri incelendiğinde, modelin artıklarının sınır içinde kaldığı yani kararlı olduğu görülmektedir. Buna ek olarak cari açık ve bütçe açığı değişkenlerine ait yapısal değişme olmadığı anlaşılmaktadır. Sonuç olarak, ARDL modeli ile elde edilen uzun dönem sonuçlarının anlamlı olduğu ve herhangi bir kukla değişken kullanılmadan da model tahmininin yapılabileceği vurgulanabilecektir. 
ARDL modeli ile uzun dönem tahminlerinden sonra, değişkenler arasındaki kısa dönemli ilişkinin varlığının tespit edilebilmesi için ARDL Hata Düzeltme Modeli yapılmıştır. Yapılan modele ait sonuçlar Tablo 7 'de sunulmuştur.

Tablo 7: ARDL $(1,5)$ Hata Düzeltme Modelinin Sonuçları

\begin{tabular}{|l|c|c|c|}
\hline \multicolumn{4}{|c|}{ (Bağımlı Değişken: D(GBA_SA)) } \\
\hline Değişkenler & Katsayı & t-istatistiği & Olasılık \\
\hline D(CA_SA(-1)) & 340,2193 & 2,008470 & $\mathbf{0 , 0 5 2 8}$ \\
\hline D(CA_SA(-3)) & 515,9930 & 3,552704 & $\mathbf{0 , 0 0 1 2}$ \\
\hline ECM(-1)* & $-0,981153$ & $-5,708962$ & $\mathbf{0 , 0 0 0 0}$ \\
\hline$R^{2}$ & \multicolumn{3}{|c|}{0,612826} \\
\hline Düzeltilmiş R ${ }^{2}$ & 0,557516 \\
\hline
\end{tabular}

Tablo 7'de yer verilen hata düzeltme modeli sonuçları ile cari açığın bir gecikmeli değeri ve bütçe açığı arasında uzun dönemin aksine kısa dönemde anlamlı ve pozitif bir ilişki olduğu tespit edilmiştir. Bu bulguya göre cari açıkta meydana gelecek bir artış, bütçe açı̆̆ında artışa neden olacaktır. Bu bulgulara istinaden, kısa dönemde cari açık değişkeni istatistiksel olarak anlamlıdır. Yani kısa dönemde cari açık, bütçe açığını pozitif olarak etkilemektedir.

Hata düzeltme katsayısı incelendiğinde negatif değerli olduğu ve istatistiksel açıdan anlamlı olduğu görülmektedir. Narayan ve Smyth (2005, s. 332-342)'e göre hata düzeltme katsayısının değerinin -1 ve -2 arasında olması, sistemin aniden değil ancak dalgalanarak ve her seferinde azalarak uzun dönemde dengeye geleceğini anlatmaktadır. Negatif ve istatistiksel olarak anlamlı çıkması ise, uyarlama sürecinin hızlı gerçekleştiğini vurgulamaktadır. Hata teriminin anlamlı olması kısa dönemde bütçe açığı ve cari açık değişkenlerinin arasındaki doğru yönlü nedenselliği ortaya koyarken, uzun dönem dengesinde oluşabilecek bir sapmanın yaklaşık \%98'inin her çeyrek dönemde düzeltildiği anlamına gelmektedir. Yani 1 birimlik sapmanın yaklaşık \%98'i bir sonraki dönem düzelmekte yani kısa dönemdeki dengesizlikler uzun dönemde denge haline dönüşmektedir. 


\section{Sonuç}

Yapılan çalışmada ikiz açıklar hipotezi ve ters nedensellik çerçevesinde cari açık ve bütçe açığı ilişkisi incelenmiş olup, cari açık ve bütçe açığı arasındaki etkileşim analiz edilmiştir. Bu iki değişkenin 2008 krizi ile kendini tekrar hatırlatması ve günümüzde de geçerliliğini sürdürmesi nedeniyle 2009-2020 yılları arası dönem tercih edilmiştir. Analize başlamak için ilk olarak serilerin durağanlıkları incelenmiş ve seviyeleri tespit edilmiştir. Sonraki aşamada zaman serileri şeklinde derlenen bütçe açığı ve cari açık verileri için eşbütünleşme analizi ve Gecikmesi Dağıtılmış Otoregresif (ARDL) sınır testleri uygulanmıştır. Bu testler sonucunda cari açık ve bütçe açığı değişkenleri arasında, uzun dönemde anlamlı ancak negatif sonuçlara ulaşılmışır. Bu sonuç, Türkiye'de ithal girdinin yoğun olarak kullanması sonucunda bütçe dengesinin olumsuz yönde etkilendiğini göstermektedir. Elde edilen ithal girdiler ile doğru ve verimli alanlarda üretim yapılması, ekonomik büyümeyi teşvik edecektir. Ancak Türkiye gibi gelişmekte olan ülke ekonomilerinde reel sektörün hareketlenmesi zaman alacağından, analiz sonucunda bulunan uzun dönemde cari açık ve bütçe açığı arasındaki ters yönlü ilişki bu bağlamda açıklanabilecektir.

Uzun dönem ilişkisinin açıklanmasının ardından hata düzeltme modeli uygulanmış ve bu model kapsamında iki değişken arasındaki kısa dönemli sonuçlar yorumlanmıştır. Kısa dönem bulgularına göre, cari açık ve bütçe açığı değişkenleri arasında anlamlı ve pozitif yönlü bir ilişki tespit edilmiştir. Yani cari açıkta meydana gelen artış veya azalış, kısa vadede bütçe açığını da aynı yönde etkilemektedir. Elde edilen bu sonuç, cari işlemler hedeflemesi görüşünü desteklemektedir. Yani Keynesyen teorinin aksine cari açıktan bütçe açığına doğru bir nedensellik söz konusudur. Bu nedensellik ilişkisi, Türkiye gibi dış borç ve faiz ödemeleri yüksek olan ülkelerin döviz kurundaki yükselişle birlikte bütçe açıklarını da arttırması şeklinde gerçekleşmektedir. Analiz sonucunda ulaşılan kısa dönemli sonuçlar, lyidoğan ve Erkam (2013), Diner ve Taş (2016)'ın Türkiye için yapmış oldukları çalışmaların sonuçları ile benzerlik göstermektedir. Yine Ahmed ve Akın (2019)'ın Yemen ekonomisi, Sinicakova, Sulikova ve Gavurova (2017)'nın Belçika, Finlandiya, Fransa, İrlanda, Malta ve Romanya ekonomileri için buldukları sonuçlar aynı yöndedir. 
Bu çalışmada elde edilen bulgular cari açığın bütçe açığını her iki dönem için de etkilediğini ancak aynı yönlü etkiyi yalnızca kısa vadede gösterdiğini ortaya koymaktadır. Ülkemizin gelişmekte olan bir ekonomi olduğu dikkate alındığında farklı dönemler itibariyle farklı etkilerin ortaya çıkması söz konusu olabilmektedir. Buna göre, Türkiye'de uygulanacak ekonomi politikalarının, hem ithal girdi kullanımının azalılılması yönünde hem de yabancı kaynak girişini sağlayacak şekilde planlanması yerinde olacaktır. Kısa vadede cari açıkta meydana gelen artışın bütçe açığını arttırması, uzun vadeli politika öngörüleri için avantaj sağlayabilecektir. Yapılan analiz sonuçlarından da teyit edileceği üzere, alınacak önlemler ile uzun vadede bir çözüme ulaşılabileceği ve bütçe açığının azaltılabileceği öngörülmektedir.

Hakem Değerlendirmesi: Dış bağımsız.

Çıkar Çatıșması: Yazar çıkar çatıșması bildirmemiștir.

Finansal Destek: Yazar bu çalışma için finansal destek almadığını beyan etmiştir.

Peer-review: Externally peer-reviewed.

Conflict of Interest: The author has no conflict of interest to declare.

Grant Support: The author declared that this study has received no financial support.

\section{Kaynaklar/References}

Ahmed, S. H. M. ve Akın F. (2019). Bütçe açığı ile cari işlemler açığı arasında nedensellik ilişkisi: Yemen uygulaması. İs ve Hayat, 5(9), 112-129.

Altunöz, U. (2014). İkiz açık hipotezinin geçerliliğinin sınır yöntemiyle sınanması: Türkiye örneği. Adıyaman Üniversitesi Sosyal Bilimler Enstitüsü Dergisi, 17, 425-446.

Alkswani, M. A. (2000). The twin deficits phenomenon in petroleum economy: Evidence from Saudi Arabia. In seventh annual conference, Economic Research Forum (ERF), Amman, 2-25.

Bakarr, T. A. (2014). Fiscal deficits and current account imbalances: Evidence from Sierra Leone. International Journal of Business and Social Science, 5(8), 256-269.

Barışık, S. ve Demircioğlu, E. (2012). Türkiye'de döviz kuru rejimi, konvertibilite, ihracat-ithalat ilişkisi (1980-2001). 17. Uluslararası Yönetim iktisat ve Issletme Dergisi, 2(3), 71-84.

Barışık, S. ve Kesikoğlu, F. (2010). Makro ekonomik değişken olarak bütçe açığı-cari açık ilişkisi: Gelişmekte olan piyasalar örneği. İktisat Işletme ve Finans, 25(294), 109-127.

Barro, R.J. (1989). The Ricardian approach to budget deficits. Journal of Economic Perspectives, 3(2), 37-54.

Barro, R. J. (1974). Are government bonds net wealth?. Journal of Political Economy, 82(6), 10951117.

Bilgili, E. ve Bilgili, F. (1998). Bütçe açıklarının cari işlem dengesi üzerindeki etkileri: Teori ve uygulama. İsletme-Finans Dergisi, 146, 4-16. 
Bolat, S., Belke, M. ve Aras, O. (2011). Türkiye'de ikiz açık hipotezinin geçerliliği: Sınır testi yaklaşımı. Maliye Dergisi, 161(1), 347-364.

Brown, R. L., Durbin, J. \& Evans, J. M. (1975). Techniques for testing the constancy of regression relationships over time. Journal of the Royal Statistical Society: Series B (Methodological), 37(2), 149-163.

Çağlayan, E. (2006). Enflasyon, faiz oranı ve büyümenin yurtiçi tasarruflar üzerindeki etkileri. Marmara Üniversitesi IiBF Dergisi, 1, 423-438.

Dickey, D. A. \& Fuller W. A. (1981). Likelihood ratio statistics for autoregressive time series with a unit root. Econometrica. The Econometric Society, 49(4), 1057-1072.

Diner, E. ve Taş, İ. (2016). İkiz açık hipotezi: Türkiye'de teorik ve ampirik inceleme. Akademik Sosyal Araştırmalar Dergisi, 32, 372-390.

Eğilmez, M. (2018). Küresel Finans Krizi. İstanbul, Remzi Kitabevi.

Erdinç, Z. (2008). İkiz açıklar hipotezinin Türkiye'de 1950-2005 yılları arasında eşbütünleşme analizi ve Granger nedensellik testi ile incelenmesi. Anadolu Üniversitesi Sosyal Bilimler Dergisi, 8(1), 209-222.

Feldstein, M. (1992). Analysis: The budget and trade deficits aren't really twins. Challenge, 35(2), 60-63.

Frankel, J. (2006). Twin deficits and twin decades. The Macroeconomics of Fiscal Policy, MIT Press: Cambridge MA., 2-16.

İyidoğan, P. V. ve Erkam, S. (2013). İkiz açıklar hipotezi: Türkiye için ampirik bir inceleme (19872005). Pamukkale Üniversitesi SBE Dergisi, (15), 39-48.

Kılavuz, E. ve Dumrul, Y. (2012). İkiz açıklar hipotezinin geçerliliği: Teori ve uygulama. Atatürk Üniversitesi İktisadi ve İdari Bilimler Dergisi, 26(3-4), 239-258.

Kim, C. H. \& Kim, D. (2006). Does Korea have twin deficits?. Applied Economics Letters, 13(10), 675- 680.

Kör, E. (2012). İkiz açıklar hipotezi: Türkiye örneği (Yüksek Lisans Tezi ). Ankara Üniversitesi Sosyal Bilimler Enstitüsü, Ankara.

Mangır, F. (2012). Türkiye için ikiz açıklar hipotezi testi (1980-2011), Academic Review of Economics \& Administrative Sciences, 5(2), 136-149.

Mankiw, N. G. (Ömer Faruk Çolak (Ed.). (2017). Makroekonomi, Efil Yayınevi.

Marinheiro, C. F. (2008). Ricardian equivalence, twin deficits, and the Feldstein-Horioka puzzle in Egypt. Journal of Policy Modeling, 30(6), 1041-1056.

Mucuk, M. (2008). Bütçe ve cari işlemler dengesi arasındaki ilişki: Türkiye örneği (1989-2004) (Doktora Tezi). Selçuk Üniversitesi Sosyal Bilimler Enstitüsü, Konya.

Narayan, P. K. \& Smyth R. (2005). What Determines migration fows from low-income to high income countries? An empirical investigation of Fiji-U.S. migration 1972-2001. Contemporary Economic Policy, 24(2), 332- 342.

Nkoro E. \& Uko K,A. (2016). Autoregressive distributed lag (ARDL) cointegration technique: Application and interpretation. Journal of Statistical and Econometric Methods, 5(4), 63-91. 
Öruç, E. (2017). İkiz açık hipotezinin Türkiye için testi: Stock-watson yöntemi ile uzun dönemli analiz (1950-2015). Gümüşhane Üniversitesi Sosyal Bilimler Enstitüsü Elektronik Dergisi, 8(19), 261-281.

Pesaran, M. H., Y. Shin \& R. J. Smith (2001). Bounds Testing Approaches to The Analysis of Level Relationships. Journal of Applied Econometrics, 16, 289-326.

Phillips, P. \& Perron, P. (1988). Testing for a unit root in time series regression. Biometrika, 75(2), .335 346.

Sinicakova, M., Sulikova, V. \& Gavurova, B. (2017). Twin deficits threat in the European Union. E a M: Ekonomie a Management, 4 (1), 144-156.

Summers, L. H. (1988). Tax policy and international competitiveness. In International aspects of fiscal policies. University of Chicago Press, 349-386.

Utkulu, U. (2003). Türkiye'de bütçe açıları ve diş ticaret açıları gerçekten ikiz mi? Koentegrasyon ve nedensellik bulguları. Dokuz Eylül Üniversitesi Iktisadi ve İdari Bilimler Fakültesi Dergisi, 18(1). 45-61.

Üzümcü, A. ve Kanca, O. C. (2013). İkiz açık hipotezi: Türkiye üzerine bir uygulama (1980- 2012). Inönü Üniversitesi Uluslararası Sosyal Bilimler Dergisi, 2(1), 17-42.

Turan, T. ve Karakaş, M. (2017). İkiz açıklar hipotezine doğrusal olmayan sınır testi yaklaşımı. Maliye Dergisi, 173, 211-227.

Yanık, Y. (2006). The twin deficit hypothesis: an empirical investigation.( Yüksek Lisans Tezi). Orta Doğu Teknik Üniversitesi Sosyal Bilimler Enstitüsü, Ankara. 
